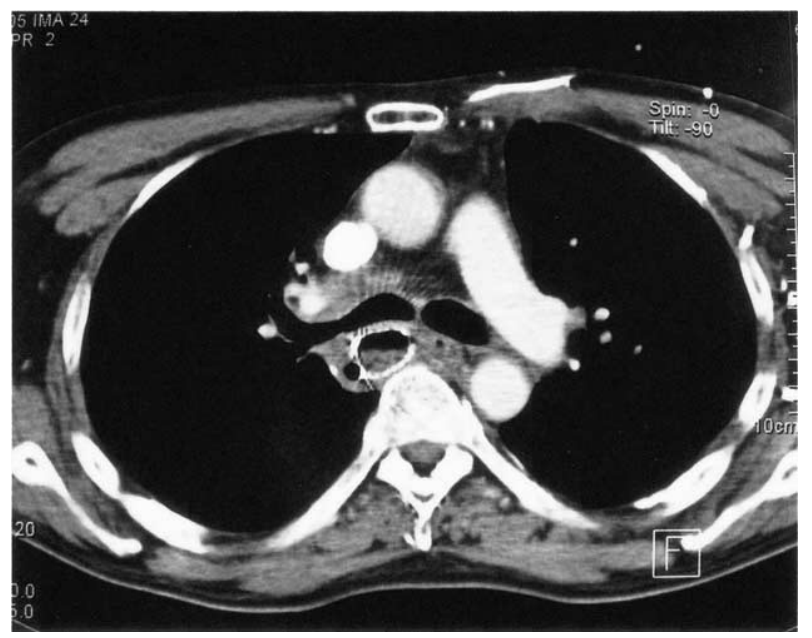

Figure 2. Preoperative CT scan. The metallic wall-stent prosthesis compresses the anterior wall of the gastric tube against the "pars membranacea" of the right main bronchus.

bronchial tree or after endoscopic dilatation of a benign anastomotic stricture. Other causative factors have only been reported as solitary cases. ${ }^{4}$ Among these, we have found in the literature just 1 other case in which the tracheogastric fistula presented in association with an auto-expandable esophageal wall-stent prosthesis. ${ }^{5}$

Symptoms at presentation may range from mild to life-threatening. ${ }^{3,4}$ Yet the possibility of a rapid deterioration of the patient's general condition should always be kept in mind. Just on suspicion, a barium esophagogram should promptly be performed for diagnosis. Treatment is always challenging and has to be individually tailored. It will depend on the severity of symptoms, on the size and location of the fistula, and on accompanying conditions. If surgery is required, the procedure of choice is excision of the fistula and closure of the tracheal and esophageal defects. Interposition of a pedicled pleural, omental, or muscle flap has proved to be useful in preventing recurrence of the fistula. The gastric tube should be left in place unless judged as an unviable option. In such case, colonic interposition is indicated to restore the continuity of the gastrointestinal tract. If mediastinitis is present, elimination of the septic focus and extensive drainage of the mediastinum are mandatory. ${ }^{3,4}$

\section{References}

1. Jeyasingham KJ. Benign strictures of the esophagus. In: Shields TW, LoCicero J III, Ponn RB, editors. General thoracic surgery. 5th ed. Philadelphia: Lippincott Williams \& Wilkins; 2000. p. 1865-80.

2. Law S, Fok M, Chu KM, Wong J. Comparison of hand-sewn and stapled esophagogastric anastomosis after esophageal resection for cancer. A prospective randomised controlled trial. Ann Surg. 1997;226: 169-73.

3. Gudovsky LM, Koroleva NS, Biryukov YB, Chernousov AF, Perelman MI. Tracheoesophageal fistulas. Ann Thorac Surg. 1993;55:868-75.

4. Buskens JC, Hulscher JBF, Fockens P, Obertop H, van Lanschot JJB. Benign tracheo-neo-esophageal fistulas after subtotal esophagectomy. Ann Thorac Surg. 2001;72:221-4.

5. Schowengerdt CG. Tracheoesophageal fistula caused by a self-expanding esophageal stent. Ann Thorac Surg. 1999;67:830-1.

\title{
Bipulmonary transplants with lungs obtained from two non-heart- beating donors who died out of hospital
}

\author{
José Ramón Nuñez, MD, PhD, ${ }^{a}$ Andrés Varela, MD, PhD, ${ }^{\mathrm{b}}$ Francisco del Río, MD, ${ }^{a}$ Pablo Gámez, MD, ${ }^{b}$ \\ Joaquín Calatayud, MD, ${ }^{a}$ Mar Córdoba, MD, ${ }^{\text {b }}$ Florentino Hernando, MD, ${ }^{a}$ Piedad Ussetti, MD, ${ }^{\mathrm{b}}$ Ana Gómez, MD, \\ Maria Cruz Carreño, MD, ${ }^{\mathrm{b}}$ Antonio Torres, MD, PhD, ${ }^{\mathrm{a}}$ Javier Gómez, MD, ${ }^{\mathrm{b}}$ José Luis Balibrea, MD, PhD, and \\ Ana López, MD, ${ }^{\mathrm{b}}$ Madrid, Spain
}

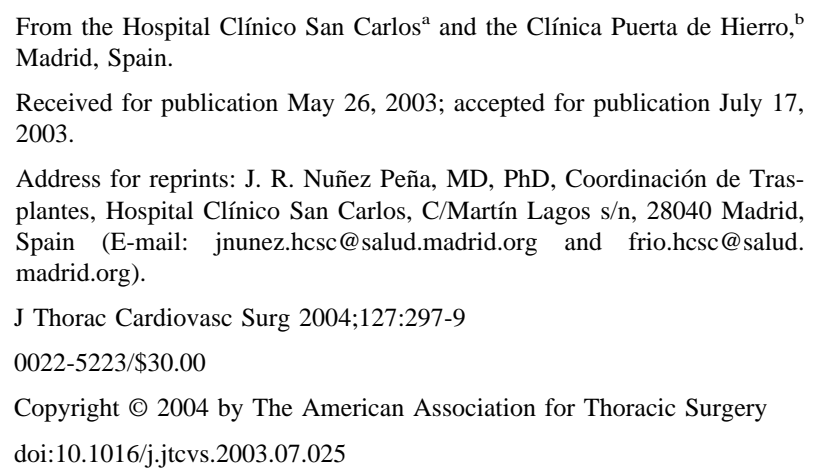

I $\mathrm{n}$ Madrid there is a specific protocol (code 9) that allows out-of-hospital emergency service personnel and transplant teams of Hospital Clínico San Carlos (HCSC) to harvest organs from non-heart-beating donors (NHBDs) for transplantation. We have reported on the quality of kidneys obtained from NHBDs. ${ }^{1,2}$ On the basis of the first medical report of a lung transplant from an $\mathrm{NHBD},{ }^{3}$ we conducted a clinical, functional, and histologic study in collaboration with the Thoracic Surgery Service of Clínica Puerta de Hierro to prove the quality of lungs from NHBDs.

\section{Clinical Summary}

After 30 minutes of cardiopulmonary resuscitation maneuvers are performed in the potential donor, the medical staff assesses cardiac 


\section{TABLE 1. Donor inclusions criteria for "code 9"}

\section{Time of cardiac arrest}

Cardiopulmonary resuscitation maneuvers in $<10 \mathrm{~min}$

Age 7-55 years (7-40 y for liver and 7-50 y for lung)

Cause of death known or supposed

Nonbleeding injuries in thorax and abdomen

Healthy aspect with no evidence of risk factors for AIDS

Assistance time $<90$ min (hospital transfer included)

No thoracic trauma (for lung transplant only)

AIDS, Acquired immune deficiency syndrome.

TABLE 2. Functional blood oxygenation analysis in operating room before lung extraction in control cases and actual donors

\begin{tabular}{lccc}
\hline Patient & $\begin{array}{c}\mathbf{P 0}_{2} \text { pulmonary } \\
\text { artery } \\
(\mathbf{m m ~ H g})\end{array}$ & $\begin{array}{c}\mathbf{P o}_{2} \text { left } \\
\text { atrium } \\
(\mathbf{m m ~ H g})\end{array}$ & $\begin{array}{c}\mathbf{P o}_{\mathbf{2}} \text { increase } \\
(\mathbf{m m ~ H g})\end{array}$ \\
\hline 1 & 160 & 600 & 440 \\
2 & 210 & 698 & 488 \\
3 & 64 & 823 & 759 \\
4 & 140 & 230 & 90 \\
Actual donors & 52 & 626 & 574 \\
& 17 & 512 & 495 \\
\hline
\end{tabular}

death and establishes the compliance with standard selection criteria (Table 1). The transplant coordinator of HCSC is notified, and the patient is transferred to a hospital in a mobile intensive care unit while receiving cardiopulmonary resuscitation. At the donor's arrival, death is certified, judicial and family permission are obtained, and a chest x-ray film and blood samples are taken. A bolus of heparin is administered. After the cadaver is taken to the operating room, 2 catheters are placed at the femoral vein and artery, and $300 \mathrm{~mL}$ of blood are obtained and preserved in a sterile transfusion bag. Afterward, a venous cannula is connected to a circuit that includes a membrane oxygenator and a variable flow rolling pump. The arterial cannula and a heat exchanger are also connected to the oxygenator, and cardiopulmonary bypass with deep hypothermia $\left(4^{\circ} \mathrm{C}\right)$ and oxygenation is established.

Specific preservation maneuvers for lungs are the placement of 2 pleural drainage tubes and the infusion of $4 \mathrm{~L}$ of Perfadex solution at $4{ }^{\circ} \mathrm{C}$, resulting in topical cooling and complete collapse of lungs. A bronchoscopy is performed, and ventilation is stopped. A standard harvest of organs is performed. The time limit to begin extraction is 240 minutes from cardiac arrest.

Specific lung harvest is performed by placing a cannula through the main pulmonary artery and another in the left atrium. The lungs are re-expanded by use of mechanical ventilation. Biphasic preservation begins with the perfusion of Perfadex solution mixed with the stored $300 \mathrm{~mL}$ of blood through the pulmonary artery. Pulmonary artery and left atrium blood gas samples reveal the oxygenation capacity of lungs. If the oxygenation capacity of the lungs is considered adequate in the operating room and there are no macroscopic or bronchoscopic injuries, the lungs are considered adequate for transplant. The lungs are then extracted, retrogradely perfused with $250 \mathrm{~mL}$ of Perfadex solution in each vein, and

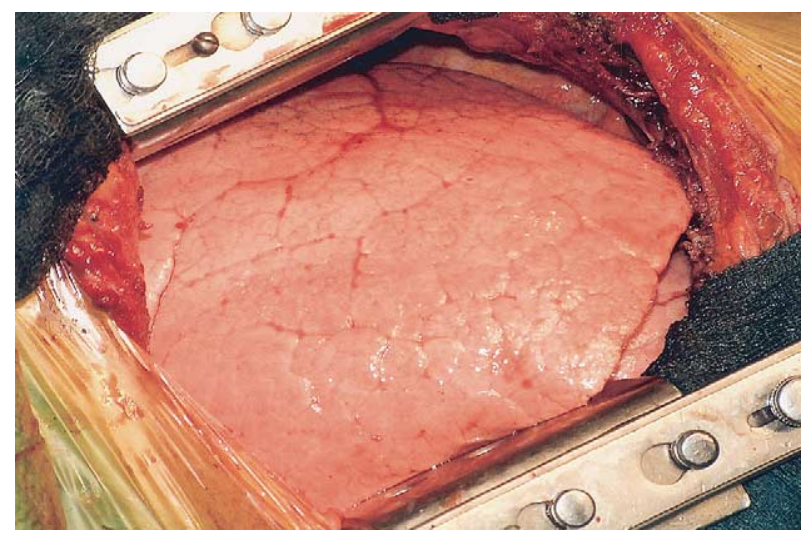

Figure 1. Macroscopic aspect of donor's lung once implanted in recipient.

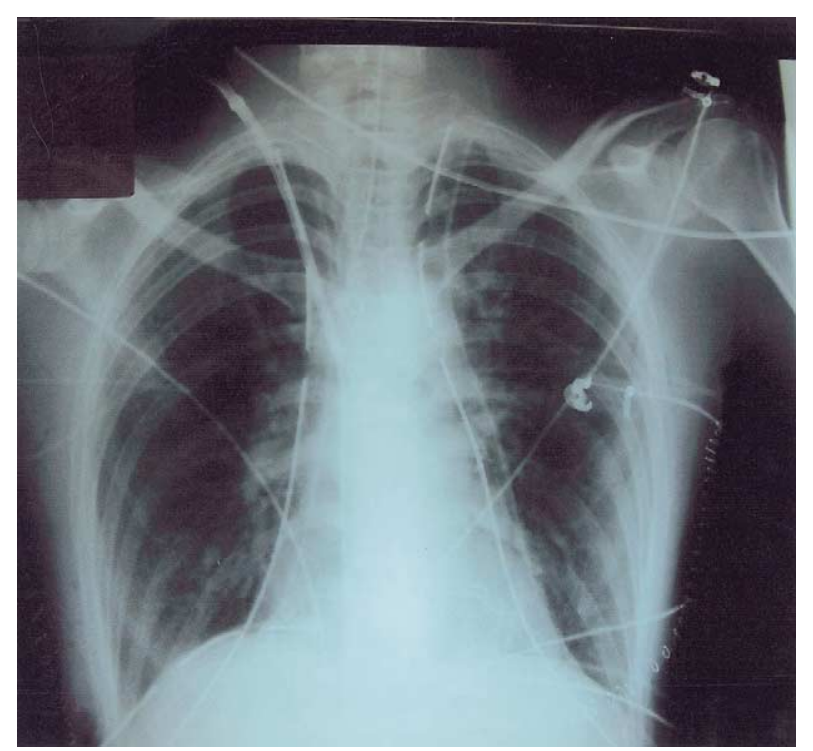

Figure 2. Chest x-ray film of first recipient immediately after transplant.

preserved in the same solution in a cold-storage system for later implantation.

We obtained 8 lungs according to the prior protocol for functional and histologic study purposes. Excellent macroscopic and histologic aspects were determined in all cases. The oxygenation capacity of the lungs was considered good in all cases (Table 2).

PATIENT 1. A 21-year-old man died suddenly. Our hospital emergency service determined the presence of asystole. The potential donor was transferred to HCSC according to code 9 protocol. There was a potential recipient in Clínica Puerta de Hierro. The recipient was asked to accept and sign the specific informed consent form, and then bipulmonary transplantation was performed (Figures 1 and 2). She was discharged 25 days later and is healthy 8 months later. 


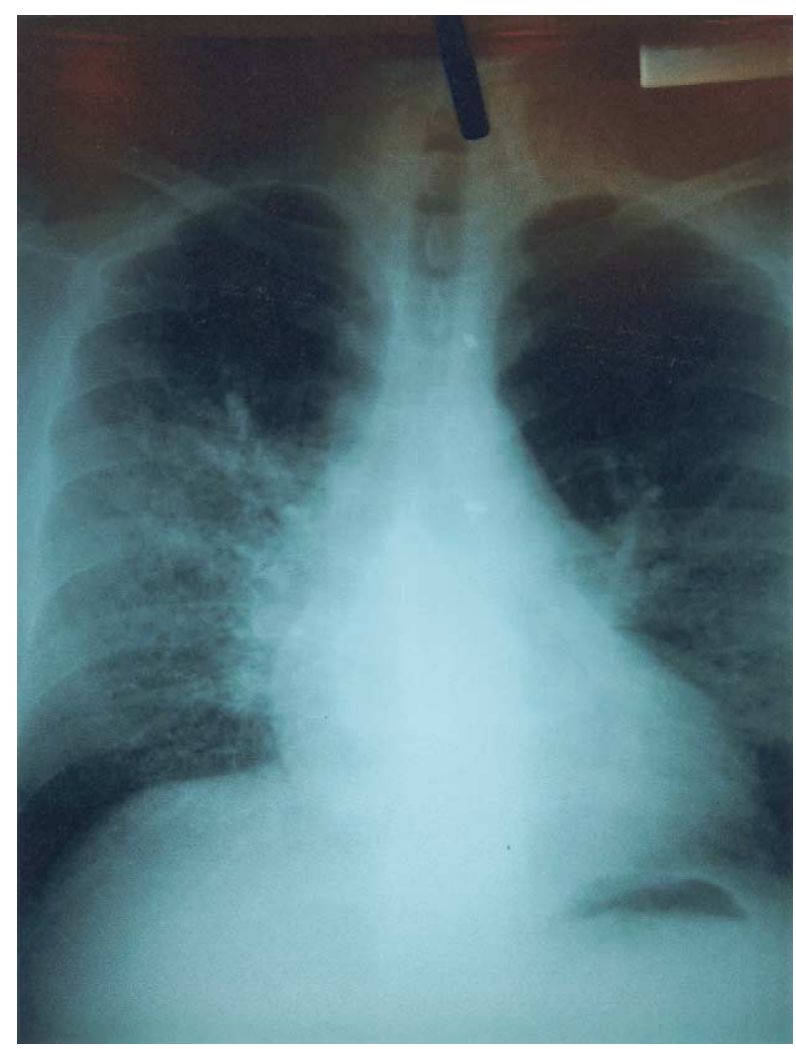

Figure 3. Chest $x$-ray film of recipient before transplant.

PATIENT 2. A 53-year-old man with no known medical previous antecedents died suddenly at home. After permission was obtained from the family and judge, organ harvesting was performed. The donor's lungs were implanted into a 30-year-old man who had lung fibrosis in relation to a crack-smoking habit. No surgical or anesthetic incidences occurred, and the patient was discharged from the hospital after 45 days (Figures 3 and 4).

\section{Discussion}

NHBDs are an excellent source of organs for transplantation. ${ }^{4}$ They are younger than EDD and compliant with strict selection criteria. Kidneys obtained from NHBDs have been proved to be at least as good as those obtained from EDD. One of the most important undesirable effects of EDD is the variable period of time

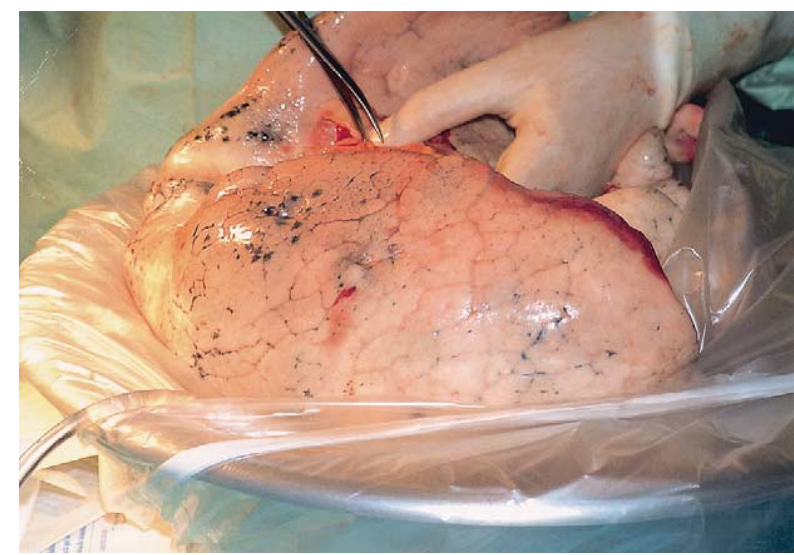

Figure 4. Macroscopic aspect of donor's lung before transplant.

that mechanical ventilation is administered, with a high incidence of infection. Conversely, at the moment of cardiac arrest, lung vasculature contains oxygen-rich blood and the aerial space is filled with fresh air, so the cellular nutrition of alveolocapillary membrane is well preserved. Lungs are organs with elastic properties and a low metabolic rate that is decreased through preservation cooling.

\section{Conclusion}

We believe that lungs are especially good organs to transplant from NHBDs. The long transplantation waiting lists worldwide justify the development of new transplant policies to increase the donor pool. Kidneys, livers, lungs, and tissues obtained from NHBDs have proved to be excellent for transplant purposes. ${ }^{5}$

\section{References}

1. Sánchez AI, Prats D, Torrente J, et al. Renal transplantation from non-heart beating donors: a promising alternative to enlarge the donor pool. J Am Soc Nephrol. 2000;11:350-8.

2. Alvarez J, del Barrio R, Arias-Díaz J, et al. Non-heart-beating donors: estimated actual potential. Transplant Proc. 2001;33:1101-3.

3. Steen S, Sjoberg T, Pierre L, et al. Transplantation of lungs from a non heart beating donor. Lancet. 2001;357:825-9.

4. Weber M, Dindo D, Demartines M, et al. Transplantation from donors without a heartbeat. $N$ Engl J Med. 2002;347:248-55.

5. Varela A, Córdoba M, Serrano-Fiz S, et al. Early lung allograft function after retrograde and antegrade preservation. $J$ Thorac Cardiovasc Surg. 1997;114:1119-20. 